\title{
A Violet Bacillus from the Thames.
}

\author{
BY
}

H. MARSHALL WARD, Sc.D., F.R.S.

Professor of Botany in the University of Cambridge.

\section{With Plate VI.}

$\mathrm{O}$

$\mathrm{NE}$ of the most interesting forms of Schizomycete I have isolated from the Thames ${ }^{1}$ is a bacillar or filamentous one observed more especially in the winter, though probably present also in the summer with altered characters.

It is remarkable for producing in vigorous cultures a magnificent violet pigment of a peculiarly pure hue; in fact almost exactly the colour of dark blue violets, or of a strong solution of gentian-violet.

This species grows well and is easily cultivated at all temperatures from about $10^{\circ} \mathrm{C}$. to $25^{\circ} \mathrm{C}$., on all the ordinary solid media, and in milk and broth, though difficulties are occasionally met with in potato-cultures. Specimens in gelatine and broth-drops grow out as long filaments, often 50 to $60 \mu$ and longer, which move with an oscillating and sinuous motion, or progress slowly across the field with similar movements. These filaments are obviously segmented,

${ }^{1}$ See Proc. Roy. Soc., Vol. 1xi, I897, p. 415. The form here described is that constituting the type of Group II on p. 4I 7 .

[Annals of Botany, Vol. XII. No. XLV. March, 1898.] 
and one can see them break at the septa into bacillar rodlets from 3 to 5 or even $7 \mu$ long by about 0.75 to $0.8 \mu$ broad or a little more (Fig. 3). They are perfectly colourless, and move more rapidly than the filaments, often progressing straight forward with fairly rapid motions right across the field - say a distance of 100 to 200 times their own length,and then suddenly stop and dart backwards a short distance, and then on again. Sometimes these progressive movements are associated with a spinning on the axis, or about a central point, but more often they are straight forwards.

Specimens stained with methyl-violet show similar sizes, but if taken from older gelatine-cultures the rodlets may be very short-about I $\mu$ long by 0.75 to $0.8 \mu$ broad-and almost like cocci (Fig. I). After a year in culture, the rods are often thinner, $0.6 \mu$ or so (Fig. 2), but soon thicken up in the broth-drop at ordinary temperatures. No trace of spores could be detected; but from some experiments where old cultures were maintained at $50^{\circ} \mathrm{C}$. to $60^{\circ} \mathrm{C}$. for several hours, it appears not improbable that the coccus-like joints act in the capacity of spores, and can withstand fairly high temperatures for a short time. If this turns out to be correct, this Schizomycete may have to be classed as a Bacterium and not as a Bacillus. The rods often show three or four spore-like, bright, denser spots (Figs. I, 2).

Numerous attempts to obtain any further development in culture-cells led to negative results only. In gelatine-drops at $\mathrm{I} 8-22^{\circ} \mathrm{C}$. the growth to filaments occurs as in broth, but more slowly, and in twenty-four hours the rods and filaments are motile, slowly writhing or jerking in the liquefying drop ; the movements are obviously restricted.

Plate-cultures in gelatine at $20^{\circ} \mathrm{C}$. show colonies in fortyeight hours-visible to the unaided eye on the third daywhich are small, slightly yellowish discs, with a granular texture under a one-third objective and sometimes traces of zonal structure where submerged. Those nearer the surface break through in a conical shape, and spread their margins irregularly over the gelatine: the much more extended 
surfaces of these colonies appear granulated and rugose, as if marked with a delicate and complicated series of contours and mounds, giving a characteristic aspect, which, however, is by no means peculiar to this specific form-e.g. such colonies occur in Typhoid (Fig. 5).

In four or five days the colonies appear as milk-white, opaque, thin, discoid, smooth and glistening expansions to the unaided eye, though the microscope shows the same characters as described above. They grow very slowly, and even after ten days at $20^{\circ} \mathrm{C}$. may be still white, though somewhat thicker, like an opaque, flattened milky drop, about 4 to $5 \mathrm{~mm}$. in diameter, and slightly sinking in the now softening gelatine. They are, in fact, beginning to liquefy the latter.

About this period, also, the superficial colonies are usually beginning to show the violet pigment-though sometimes it occurs much earlier and at others is delayed-the colour appearing first as a mere trace of purplish cast on a dirtywhite matrix, gradually spreading over the colony, till the latter is deep violet or almost blue black. The pigment does not spread into the gelatine, but is strictly confined to these superficial colonies, at least for a long time. The totally submerged colonies may remain dirty-yellow, or buff-coloured, even for weeks, so that oxygen may have to do with the development of the pigment; in some cases, however, I have found them faintly purple in four or five days (cf. Figs. 4-6).

It is interesting to note that slow growth, with the formation of the pigment, occurs at temperatures even as low as $5^{\circ}$ or $6^{\circ} \mathrm{C}$. on gelatine-plates kept cool by ice.

If there are very few colonies on the plate, they may eventually dry up with the non-liquefied gelatine, and I have plates in the laboratory more than two years old where this has occurred. The hard, smooth, deep purple discoid colonies on these plates look just like dried ink-drops, each about 10-1 $2 \mathrm{~mm}$. in diameter, with irregular margins, and each surrounded with a pale zone, $2-6 \mathrm{~mm}$. broad, scooped out of the yellower dry gelatine, and representing where liquefaction 
occurred. The water having evaporated, the colonies are flattened on to the glass.

In stab-cultures in gelatine a white, button-like mass forms at the infection-point in three days at $15^{\circ} \mathrm{C}$., while minute points develop along the line of inoculation. In ten days a thistle-head funnel of liquefaction is developed, still all quite white. In eighteen days the liquefaction at the top has reached the walls of the tube, or nearly so, and the liquefied gelatine above is found to have a dense, tough membrane on its surface, the white matrix of which is turning purple. This membrane (zoogloea) lines the sides of the funnel-shaped depression, as the surface of the gelatine sinks owing to evaporation (Fig. 7 c).

In a month, at this temperature, the gelatine was liquefied about one-eighth of the distance down, and a deep violet zoogloea-membrane floated on the top, while violet flecks had fallen to the bottom of the liquid, and rested on the still solid gelatine below (Fig. $7 d$ ).

All the gelatine-tube cultures show liquefaction of the gelatine. The rate at which this progresses at $20^{\circ} \mathrm{C}$. may be estimated from the following: in six days the upper one-third of the gelatine of a stab-culture was liquefied, and with a beautiful deep violet, funnel-shaped mass of the Schizomycete tailing off below into the solid gelatine. Even after three months the gelatine is only liquefied about two-thirds down the tube, and six months' tubes may still have some gelatine solid below. The liquefied gelatine is very viscid. The thin streak in the solid gelatine was still buff in colour, apparently from lack of oxygen.

Streak-cultures on gelatine, at $15^{\circ}-20^{\circ} \mathrm{C}$., grow fairly rapidly. In twenty-four hours at $15^{\circ} \mathrm{C}$. a white opaque streak was developed, which in three days began to show traces of the violet pigment, and the gelatine began to soften below, so that the culture sank in. In nine days the gelatine was excavated by a large scoop-like cavity, filled with viscid liquid (the surface being kept flat by inclining the tube till nearly horizontal) on which floated a deep violet membrane, while 
Ward.-A Violet Bacillus from the Thames. 63

in the liquid itself flecks of white and violet colonies were floating or sunk to the bottom (Fig. 8). In three or four months all the gelatine is liquefied, and dirty-violet flecks are floating in the liquid

Closer examination shows that the violet mass is composed of a complex folded and wrinkled zoogloea-form, and that the pigment is confined entirely to this, and does not diffuse into the liquefied gelatine in which the trembling jelly-like mass floats. These zoogloea-masses are found scooping out cavities in the otherwise solid gelatine, and lining them with the folded membrane. Later on, the liquefaction slowly spreads away from the zoogloea, but the pigment is confined to the latter. The same occurs, somewhat more rapidly, at $20^{\circ} \mathrm{C}$. On removing the zoogloea-membrane, these cavities are left apparently devoid of Bacilli; but the microscope shows their presence in abundance, and in a few days those remaining have multiplied and again covered the concave surfaces with the membrane, which soon thickens, wrinkles, and obtains the violet colour as before. When the gelatine is completely liquefied, the violet colour is confined to the membrane at the surface, or to pieces of it which sink in: the non-oxygenated submerged Bacilli forming a precipitate at the bottom are buff or greyish-yellow, or even dirty-white.

On agar, at $20^{\circ} \mathrm{C}$., a thick white or slightly buff opaque streak forms in twenty-four hours or so, and in three days has a waxy appearance, often with raised margins. On the fourth day the purple colour begins to show here and there in the white, and in ten days the whole surface of the agar may be covered with an intensely deep purple, corrugated membrane, which is very tough and may be lifted off bodily from the medium. Underneath, the growth is still white, and the colour is confined to the zoogloea-mass-it never diffuses into the agar (Fig. 9). In feeble cultures the growth may be so slow as scarcely to extend beyond the path traced by the inoculating needle; but here too, the deep, ink-like, purpleblack drops soon appear as before.

On potatoes, at $20^{\circ} \mathrm{C}$., a thickish, dirty-white streak, tinged 
with grey or yellowish-brown, forms in from two to five days, and slowly spreads; it varies considerably as to thickness, wet or dry appearance, and rate of growth (Fig. IO). Generally, but not always, the violet colour begins to appear about the fourth day, and then invades the mass, and a tough, deep violet, corrugated and mamillated membrane is formed as on agar, but not so extensively. In some cases the cultures on potatoes fail altogether to produce the pigment, and I am unable to say why. Very often the violet colour does not extend to the edges, but remains towards the centre.

In broth, at $20^{\circ} \mathrm{C}$., turbidity is just perceptible on the second day, and this increases. Later on a thick membrane forms above, the liquid below being very turbid. The membrane is at first white, and may remain so for ten days or more. In strong cultures the violet hue appears sooner or later, and in twenty days there is a tough, much corrugated, violet membrane floating on the still turbid liquid, at the bottom of which a white deposit collects. The colour of the membrane deepens as the culture ages, and it clings so tightly to the walls of the tube that the liquid does not escape on upturning.

Broth at $35^{\circ}$ gives no growth in four or five days-the liquid is perfectly clear.

Carrot at $25^{\circ} \mathrm{C}$. Spreads as a white film in forty-eight hours, and in three days is a purple and white paste. In fifteen days much spread as a white, wet, pasty layer, but only small patches of purple here and there.

Artichoke at $25^{\circ} \mathrm{C}$. Much as on carrot, but perhaps more waxy. In fifteen days the white wet paste is smeared with blue-violet patches.

Milk undergoes slight coagulation, and the separated casein is slowly peptonized, or peptonization may occur without evident precipitation. The reaction of the liquid is alkaline. After some time-it may be three or four weeks - the violet pellicle forms on the surface, deepening in colour from day to day. In some cases, at $25^{\circ} \mathrm{C}$., traces of violet occur above in a week, and in the deposit in a fortnight, and still no change is evident in the milk, except a grey colouration and 
marked alkalinity. The grey colour is due to the spreading of the purple through the milk. In a month nearly all is peptonized, and the liquid purple and very strongly alkaline.

The colouring pigment cannot be detected in the Bacilli themselves under the microscope, but seems to be in the membrane-the swollen cell-walls forming the zoogloea-matrix -or even external to this. It is hardly, if at all, soluble in water, as is shown by the fact that on filtering water in which large quantities of the purple flecks \&c. have been crushed, the liquid comes off quite or nearly clear; but it is readily dissolved out by absolute alcohol. This alcoholic solution is, moreover, extremely stable, and I have kept a tube half full of it for more than six months unaltered in the dark at ordinary (spring and summer) temperatures. The beautiful blue-violet colour has a slight reddish cast in it, reminding one exactly of a solution of gentian-violet.

The alcoholic solution shows one broad absorption-band, extending from the red to the green-blue; but even a layer half-an-inch thick lets some of all the rays through.

Acetic acid slowly renders the alcoholic solution paler. $\mathrm{NaHO}$ turns it bluish-green, the violet colour returning, but paler, with slight excess of $\mathrm{HCl}^{1}{ }^{1}$ On evaporating the alcoholic solution to dryness over a water-bath, the purple sediment dissolves up again in alcohol apparently unaltered. Stable as it thus is, however, the solution exposed to the bright sunlight of an August day is completely bleached in from one to two hours.

Old milk-cultures yielded Bacilli, the gelatine-colonies from which grew well, but were quite colourless, and very like those of $B$. Coli communis. It required several passages through broth and gelatine to get the colour up again.

I have made numerous experiments with this Schizomycete to determine its relations to light, and find it one of the most sensitive as yet tried. It is quite easy to obtain sun-prints with agar-plates over which a stencil-letter is placed, with

1 Practically the same reactions were observed by Macé with the violet pigment from his B. violaceus (Traité pratique de Bactériologie, I892, p. 54I). 
a couple of hours' exposure on a spring day. I have also attained fairly satisfactory results in bright sunshine by placing a plate behind an ordinary photographic negative: the print was slightly wanting in sharpness, because of course I had to have a plate of sterilized glass between the agar-film and the negative; but in cases where the glass was thin enough the picture was very good indeed.

Tubes of water containing large quantities of this Bacillus, can be almost completely sterilized by a few hours' exposure to sunshine. No doubt the question of temperature comes in in all these cases, but it must be noted (I) that I have kept them alive for four or five hours in a hanging-drop at 30 to $35^{\circ} \mathrm{C}$., and (2) that in the experiments with the solar and electric spectra, where the exposures are made over ice, the maximum light-effect is not towards the red end at all, but in the blue-violet. I therefore regard these bactericidal effects as due to the blue-violet light-rays, and not to the high temperature.

I have made numerous attempts to watch and measure the growth and division of the rodlets, but although I have been able to convince myself that the filaments segment up into the short rodlets, the fact that both filaments and rodlets are moving actively in all the available media, as soon as the light is turned on them ${ }^{1}$, though in some cases at any rate they seem to become quiescent again in the dark, has completely baffled all my endeavours. These movements seem to depend on a fairly high temperature-20 to $25^{\circ} \mathrm{C}$. or so-and I should say the divisions are completed about every twenty minutes or so $^{2}$. The shorter segments (Bacilli) often move actively, each for itself, before separating from the other segmentsrarely more than four in all-of the filament, which has a slow, undulating movement as a whole. I have not investigated the question of cilia, but the character of the movements of

1 This fact had already been observed by Engelmann (Unters. aus dem Physiol. Lab. zu Utrecht, I882, p. $25^{2}$ ).

${ }^{2}$ Brefeld (Bot. Unters. IV, p. ${ }_{4} 6$ ) found that B. subtilis, at $24^{\circ} \mathrm{R}$. and under favourable conditions, divided once every thirty minutes. 
the individual Bacilli is such as to lead one to expect that each has one or more.

As already stated, I have entirely failed, after many attempts, to make this Schizomycete develop recognizable spores. In old cultures on agar or gelatine the rods and filaments, both long and short, are usually found to contain small stainable bodies, which, owing to their brightness and general appearance in the fresh preparations, are often very like spores; especially when, as frequently occurs, they lie singly in the rodlets or at regular intervals in the filaments. These are not spores, however, for they stain as readily with the ordinary bacillar dyes-such as methylene-blue and methyl-violet-as they do with carbolized fuchsin, and aniline, methyl-violet, \&c. Moreover, these stainable masses are of all sizes, and in all positions; there is nothing definite or spore-like about them. In old cultures they are also often met with in the interior of giant rods and filaments of irregular shapes, which are obviously of the nature of the so-called involution forms.

All attempts to get them to germinate have failed, and they do not withstand high temperatures: moreover, the rodlets and filaments containing them are still capable of further growth and division when placed in hanging-drops. On the evidence, therefore, I conclude that no spores are developed under ordinary conditions.

The following table exhibits a summary of the characters.

\section{ViOLET BACILlus.}

Habitat. In the Thames, especially in winter, and not a common form.

Morphological Rodlets or filaments, from $2-3 \mu$ to $60 \mu$ and upwards long by characters. about 0.75 to $0.8 \mu$ broad. Often quiescent, but may be actively motile. Involution-forms in old cultures. No spores found. In old cultures the rodlets are so short as to be almost cocci.

Gelatine-plates. Visible in about three days at $15^{-20^{\circ}} \mathrm{C}$. At first small, milkwhite, opaque, circular colonies, growing very slowly. Under the microscope they are yellowish, granular, and sometimes faintly zoned; on emerging to the surface they spread irregularly in very thin sheets, with notched margins. May be rugose and contoured like Typhoid. Violet pigment begins to show faintly about the tenth day, and the gelatine is softening and liquefying immediately 
Streak-culture At $15^{\circ}$ C. forms a white, opaque, milky streak in $24-48$ hours. on gelatine. In three days may show signs of sinking as gelatine softens, and violet hue may begin to appear along the axis. In nine or ten days the gelatine is scooped, and a violet membrane floats on the liquefied mass, in which violet and dirty-white flecks are distributed. More or less complete liquefaction of the gelatine follows, but it often requires many weeks, even at $20^{\circ} \mathrm{C}$., for completion throughout the tube.

Stab-culture in In three days at $15^{\circ} \mathrm{C}$. a small white button, like a drop of gelatine. milk, is formed at the point of inoculation, and minute white points in the tunnel. In ten days or so the button has sunk in a depression of liquefied gelatine, producing a thistle-head funnel. Culture still white. In eighteen days the liquefaction reaches nearly to the walls of the tube, the funnel being lined by a violet membrane. In about four weeks the gelatine is liquefied to one-eighth of its depth or so, a deep violet, folded membrane floating on the top and through the liquid. At $20^{\circ} \mathrm{C}$. the same phenomena are observed, but proceed more rapidly at first. It takes many weeks or even months to completely liquefy all the gelatine. Submerged in gelatine: no growth.

Agar. Forms a thick white streak in $24-48$ hours at $20^{\circ} \mathrm{C}$. which turns violet along the axis on the fourth day or later. In about ten days a magnificent corrugated, deep violet membrane is formed, which can be lifted, and shows white growth below. When water of condensation is collected, the submerged growth is white.

Potato. In from two to five days, at $20^{\circ} \mathrm{C}$, a more or less copious, dirtywhite to yellowish patch. Later on the violet colour spreads from the centre, and a corrugated, deep violet membrane is found by the tenth day. But this often does not extend to the edges, and in some cases fails altogether.

Broth. Traces of turbidity in two days at $20^{\circ} \mathrm{C}$, and by the sixth day very turbid, especially towards the top, where a thick white membrane forms. After ten or twelve days, or even earlier, the thicker membrane begins to turn violet and a white precipitate falls in the still turbid liquid, in which are violet and white flecks.

Milk. The casein is precipitated as a coagulum, and slowly dissolved. The liquid is alkaline. Later on a violet membrane forms above.

Glucose. No fermentation, and no perceptible change at all beyond a very faint turbidity during the first few days.

Air require- Aërobic.

ments. 
Temperature. The Bacilli are still alive after several days at $35^{\circ} \mathrm{C}$, but no growth is maintained; growth occurs at $5^{\circ} \mathrm{C}$. The best temperature seems to be near $20^{\circ} \mathrm{C}$. Old cultures withstand $50^{\circ}$ to $60^{\circ} \mathrm{C}$. for some hours, though no true spores are known.

Liquefaction. Liquefies the gelatine, but only slowly after the upper parts are fluid, and the deeper parts may be solid months afterwards.

Rapidity of Slow. In many cases colonies are found only 10 or $12 \mathrm{~mm}$. in growth. diameter six months after making a plate, the gelatine around having dried up; they are usually about half that diameter when the gelatine liquefies, and they float in it.

Pigment. Deep violet. Not in the cells, and does not diffuse into the solid media, except perhaps a little on potatoes. Insoluble in water; very soluble in alcohol, and looks like gentian-violet; very stable except in sunlight. Turns bluish green on adding NaHO, the original colour almost restored by excess of acid. Acetic acid to original solution makes it paler. Absorbs yellow-orange to green-blue.

Reactions to Easily killed on exposure to direct sunlight. At moderately light. high temperatures the Bacilli, quiescent in darkness, move actively when illuminated.

Pathogenicity. Prof. Kanthack finds it not pathogenic for guinea-pigs. I have to thank Prof. Kanthack for examining pathologically a large number of these Thames Schizomycetes.

Interesting and important results were obtained on reviving No. 2 from an agar-tube which had remained untouched from August 15 to June 9 , i. e. ten months.

The plate-colonies at $20-22^{\circ} \mathrm{C}$. eventually came up white and quite normal, except that they were more tough and membranous than expected, and the needle lifted each colony whole from its liquefying disc. At first they were pure white, as usual; but in ten days the purple colour appeared in the middle or at the margins, and rapidly spread. Until the purple hue appeared, I was inclined to suspect the plates were not pure, and that the colonies were those of a capsuled Bacillus.

The tube-cultures were also normal, and the purple membranes of the broth- and milk-cultures appeared on the tenth to eleventh days at $20-25^{\circ} \mathrm{C}$, so that no doubt need exist as to the species. At the same time it should be noted that some of the plate-colonies remained white or yellowish-white to the end, and that great variations were exhibited as to the degree of liquefaction and coherence of the colonies. I was 


\section{7o Ward.-A Violet Bacillus from the Thames.}

unable to determine the causes here at work, but neither temperature nor impurity of culture were among them.

It is evident that this is a well-marked Pigment-Bacterium, and at first sight one might suppose it not difficult to identify. On looking further into the matter, however, it turns out that several violet or deep blue Pigment-Bacteria are described, some of them very vaguely. So far as I have been able to discover, the following are the forms hitherto introduced into the literature. Passing over Schröter's Micrococcus violaceus ${ }^{1}$, a form described as not liquefying the gelatine, and non-motile - though in other respects it would seem to be very similar to the elliptical cocci got in old gelatine-cultures of the Thames species, and in any case it must be regarded as imperfectly described-there are at least nine or ten alleged specific forms in the handbooks, viz. B. violaceus of Plagge and Proskauer, usually regarded as identical with their B. lividus ${ }^{2}$; $B$. janthinum of $Z_{o p f}{ }^{3} ; B$. membranaceus amethystinus of Eisenberg ${ }^{4} ; B$. violaceus Laurentius of Jordan ${ }^{5} ; B$. violaceus of Frankland ${ }^{6} ;$ B. coevuleus, Smith ${ }^{7} ;$ B. coeruleus of Voges ${ }^{8}$; $B$. violaceus of Macé ${ }^{9} ; B$. berolinsis indicus of Claessen ${ }^{10}$; and $B$. indigoferus of Voges ${ }^{11}$.

Assuming these to be all autonomous forms-which, however, is extremely doubtful-I now proceed to examine their principal characters with reference to the Thames form. Frankland's species-B. violaceus - naturally suggests itself, seeing that it was also reported from the London as well as the Berlin waters; but it is noticeable that it was first observed in the Spree.

Apart from small differences as regards size and manner

1 Schröter in Cohn's Beiträge, Bd. i, p. I09; and Adametz, Die Bakterien der Nutz- und Trinkwässer, Wien, I 888.

${ }^{2}$ Zeitschr. f. Hygiene, Bd. ii, p. $463 . \quad{ }^{3}$ Die Spaltpilze, I885, p. 68.

4 Bakteriol. Diagnostik, I89I, p. 421 .

5 Report of State Board of Health, Massachusetts, I 890, p. 838 .

6 Zeitschr. f. Hygiene, Bd. vi, p. 394.

7 Medical News, 1887 , p. $75^{8}$.

8 Centralbl. f. Bakt., Bd. xiv, I 893 , p. $3 \circ 3$.

9 Annales d'hygiène publ. \&c., t. xvii, I887.

${ }^{10}$ Centralbl. f. Bakt., Bd. vii, p. I3.

11 Ibid., Bd. xiv, I893, p. 307 . 
of movement, the morphological characters of Frankland's species agree very well with mine, except that I have not observed the spores described as occurring in the agarcultures. It is true that Frankland says they only occur here and there; but since they bulge out the Bacillus, they ought to be easily seen. However, the authors give no further particulars about these spores, and so it is impossible to form any opinion concerning them. In many respects, also, there are resemblances between the Franklands' form and mine in the characters of the plate- and other colonies; but they do not refer to the zoogloea-membrane, and describe the agarcultures as forming a smooth, bright layer over the surface, and not a corrugated membrane.

Perhaps the sum of the differences gives us sufficient characters to separate the two forms, and we may say that mine differs from the Franklands' form in certain morphological characters : in forming no spores, in the marked development of zoogloea-membranes, and in the cultures on agar and potato. It might possibly be that the smooth, bright layer referred to by the Franklands is a young stage, or that they were working with a weaker form. I often find that after being some months in culture this form grows feebly on agar and potato.

The $B$. violaceus Laurentius of Jordan agrees fairly well in size $^{1}$, in forming no spores, and in some other morphological characters. The plate-colonies are very different, as are also the stab-cultures-especially as the author insists that no membrane forms above, and the gelatine rapidly liquefies in the tunnel. The cultures in milk and in broth are also markedly different.

The $B$. violaceus of Macé is believed by Macé himself ${ }^{2}$ to be the same as the Micrococcus violaceus of Schröter, and the one found by Bujwid in hail ${ }^{3}$.

${ }^{1}$ I assume that the breadth is $0.7 \mu$ and not $7 \mu$, as stated in the original (1. c. p. 838 ), obviously by a printer's error.

${ }^{2}$ Macé, Traité pratique de Bactériologie, I892, p. 541.

3 Bujwid in Ann. Pasteur Inst., 1887, p. 592. 


\section{Ward.-A Violet Bacillus from the Thames.}

Zopf's Bacterium janthinum differs in some characterssize, milk-cultures, \&c.- - but might very well pass for a feeble form of mine in other respects. Lustig ${ }^{1}$ regards Zopf's form as identical with the one found by Bujwid in hail, and agrees with Jordan ${ }^{2}$ that it is the same as one previously found by Hueppe. Jordan also points out the resemblances between Zopf's form and Rosenberg's Bacterium $h .^{3}$, as well as the doubts as to what the latter is-possibly identical with Frankland's B. violaceus or with Jordan's B. violacens Laurentius. Zopf's $B$. janthinum has been found often in water, e.g. by Plagge and Proskauer ${ }^{4}$, Roszahegyi ${ }^{5}$, Jordan ${ }^{6}$, \&c. The latter also discusses the difference between the three forms last mentioned.

As regards Smith's B. coevuleus, from the Schuylkill, if the colouring-matter is really formed in the cells, as stated, and is insoluble in alcohol, there is no doubt a sufficient difference; moreover, the pigment is a blue one, and we may safely regard this as a distinct form on the evidence to hand.

Claessens' B. berolinsis indicus, from the Spree, also produces a blue (indigo) pigment, insoluble in alcohol, and many other differences exist, in addition to its not liquefying the gelatine and not rendering broth turbid ${ }^{7}$, which suffice to distinguish it.

Voges' B. coeruleus is too stout and short for my form, and again the pigment is a different colour-blue, not violet-and does not form in broth. The agar- and milk-cultures are also decidedly different. Moreover, the colour is soluble in water. There can be no doubt this form is quite different from the one I have isolated from the Thames.

Voges' B. indigoferus is still more different, and especially in its minute size.

There remains Eisenberg's B. membranaceus amethystinus. The differences between this form and mine are so few and

${ }^{1}$ Diagnostik der Bakterien des Wassers, I 893, p. $76 . \quad{ }^{2}$ l. c., p. 84 I. ${ }^{3}$ Ueber die Bakterien des Main-wassers, Arch. f. Hyg., Bd. v, p. $45^{8}$.

${ }^{4}$ Zeitschr. f. Hyg., Bd. ii, p. $45^{8}$.

${ }^{6}$ l. c., p. 840 . 
so trivial that I am strongly inclined to regard them as accidental. Eisenberg's description of the plate- and other gelatine-cultures, of the development of the membrane on agar and broth, absence of spores, and so on, are quite like mine; but the rods are extremely short, and non-motile, though their thickness agrees very well. His description of the potato-cultures also agree with some of mine, though in other cases I find the pigment developed on these also.

On the whole, it seems pretty certain that this violet Bacterium from the Thames is, then, the one found by Jolles in water, and named B. membranaceus amethystinus by Eisenberg.

Other Pigment-Bacteria, with blue or violet hues, are referred to in the literature, but the descriptions are so incomplete that I cannot compare them. Thus Schröter's B. Lacmus ${ }^{1}$, Ehrenberg's B. syncyanus ${ }^{2}$, Beyerinck's B.cyaneofuscus $^{3}$, forms a blue pigment in one of its stages, but does not properly come under the head of violet Bacteria. What Jordan's $B$. cyanogenus ${ }^{4}$ is, and whether it is the same as Hueppe's ${ }^{5}$ Bacillus of blue milk, I cannot decide, but both may safely be regarded as distinct from any of the forms referred to, and the pigment is quite different. The same is true of Alvarez' $B$. indigogemus ${ }^{6}$, and so far as I can discover these exhaust the list of blue and violet PigmentBacteria.

It not unfrequently happens that plate-colonies refuse to colour. I have made numerous attempts to determine the cause of this. Exposure to light, and cultivation at too high a temperature, may bring it about, and in one series I had it in culture for nearly a year as a white or slightly yellowish form which refused to form the violet pigment. Eventually, however, the colour appeared in a milk-culture, and was

${ }^{1}$ Pilz. Schles., p. I 58, referred to by De Toni and Trevisan in Saccardo's Syll., Vol. viii, p. 978.

2 Verhandl. d. Berl. Akad., I840, p. 202, and Saccardo, 1. c., p. 979.

${ }^{3}$ Bot. Zeit., I891, No. 43 .

${ }^{4}$ Jordan, 1.c., p. 832 .

5 Mitth. aus dem Kaiserl. Ges., Bd. ii, p. 355 (see also Heim, ibid., Bd. v, p. 5 I 8 ).

${ }^{6}$ Sternberg, Bacteriology, I 893, p. 476. 
regained more and more on transference. In some cases, however, the non-pigmented variety appeared on normal plates, and I was quite unable to refer it to any cause. This white variety would probably repay further study.

In any case I think the evidence is against the multiplicity of species of violet Bacteria which now exist in the literature. At the same time, the difficulties of microscopic cultures of the present form, and the lack of information regarding them in other alleged 'species' or forms, should make us hesitate before we decide as to the autonomy of any, since it may be taken as certain that we do not know the whole life-cycle of even a single member of this type.

\section{EXPLANATION OF FIGURES IN PLATE VI.}

Illustrating Professor Ward's paper on a violet Bacillus.

Fig. I. Rodlets from fresh gelatine $(a)$ not stained; $(b)$ similar rodlets stained with methylene-blue - the ends often stain more deeply than the centre.

Fig. 2. Rodlets, \&c., from an old Agar culture $(\alpha)$ stained with methyl-violet; (b) similar preparation from old gelatine-cultures showing 'involution-forms.'

Fig. 3. Rods and filaments from a twenty-four hours' broth-culture.

Fig. 4. Plate-colonies on gelatine after ten days' growth at $20^{\circ} \mathrm{C}$., from a culture a year old (nat. size).

Fig. 5. Plate-colonies in various stages of development on gelatine : $(a)$ after twenty-four hours at $18^{\circ} \mathrm{C}$.; $(b)$ the same on third day; (c) submerged colonies on fourth day at $18^{\circ} \mathrm{C}$. All under $\frac{1}{3} \mathrm{obj}$.

Fig. 6. Plate-colonies: (a) after ten days at $18^{\circ} \mathrm{C}$., nat. size, showing development of pigment, and liquefaction; $(b)$ the non-pigmented variety after three weeks at $18^{\circ} \mathrm{C}$.; the plate is liquefied, and cream-coloured or yellowish colonies are floating in the liquid.

Fig. 7. Stab-cultures in gelatine: $(a)$ after three days; $(b)$ after ten days, liquefaction is beginning, but the colonies are still white; $(c)$ after eighteen days, the violet pigment appearing in the funnel; $(d)$ after a month, the gelatine liquefied some way down. All at ordinary temperatures.

Fig. 8. Gelatine-streak after ten days at $5^{\circ} \mathrm{C}$.; the purple growth lies in a groove of liquefaction.

Fig. 9. Agar-culture at $20^{\circ} \mathrm{C}$.; (a) after four days, the purple colour appearing in the white, and $(b)$ on the tenth day, the white nearly all gone.

Fig. Io. Potato-culture, ten days at $20^{\circ} \mathrm{C}$, , the purple hue has only invaded part of the growth--the rest remains dirty brown in colour. 
Annats of Botany

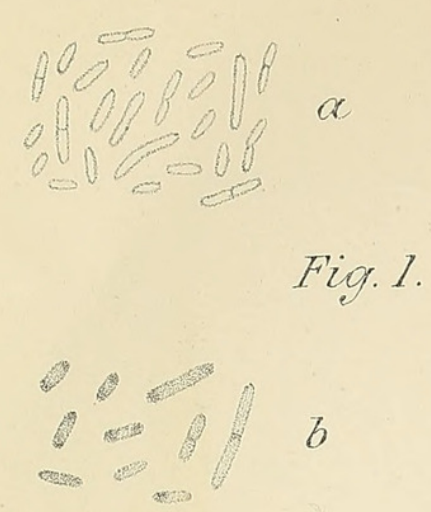

Fig. 3.

Fig. 4 .
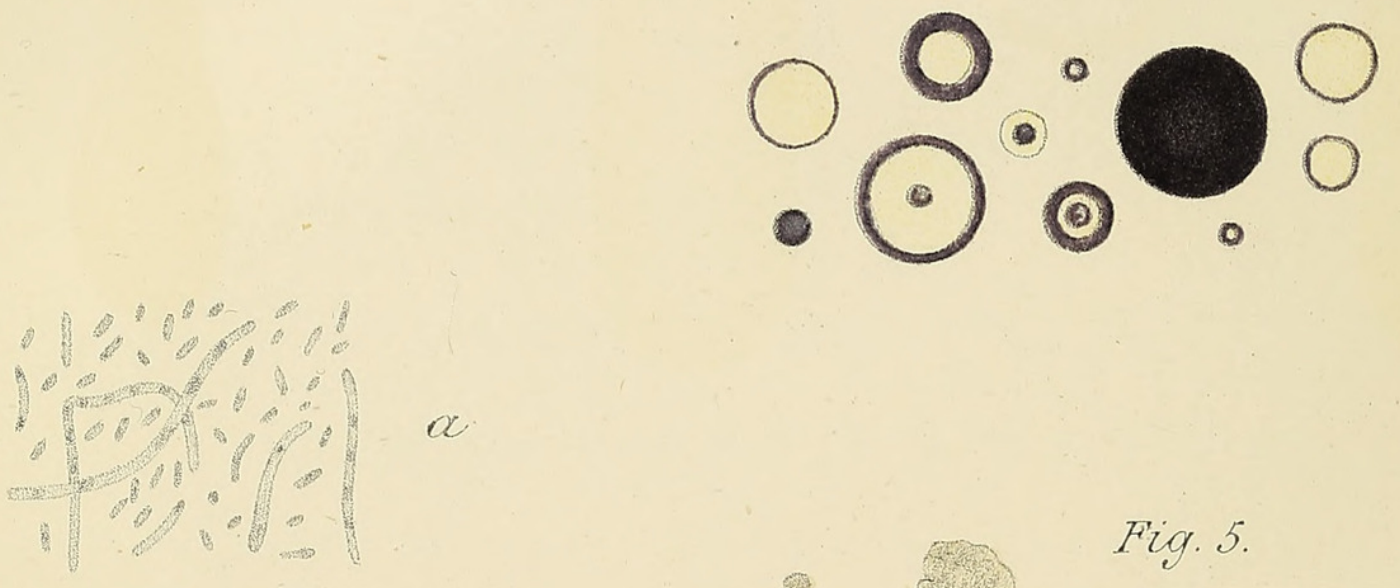

Fig. 2.

$$
0 \text { Fig.5. }
$$
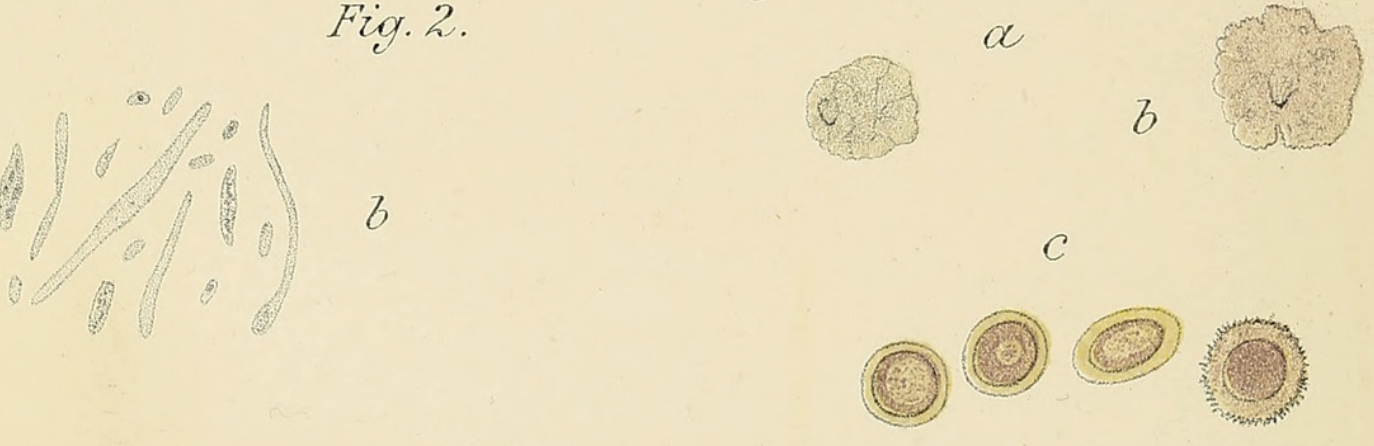

Fig. 6.

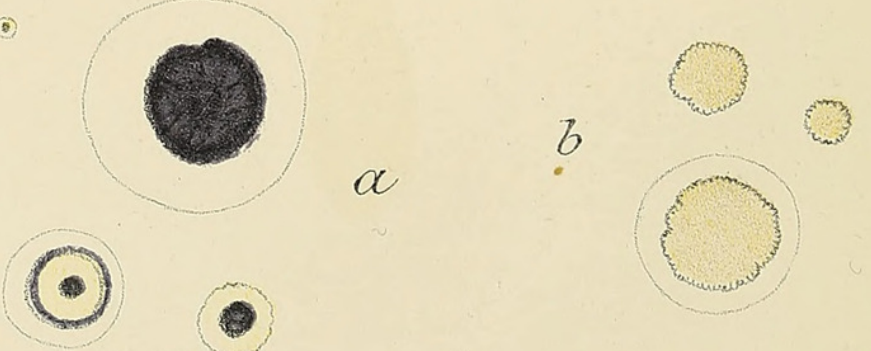

WARD. - VIOLET BACILLUS. 
Vol.XII, PI.VI.

Fig. Y.
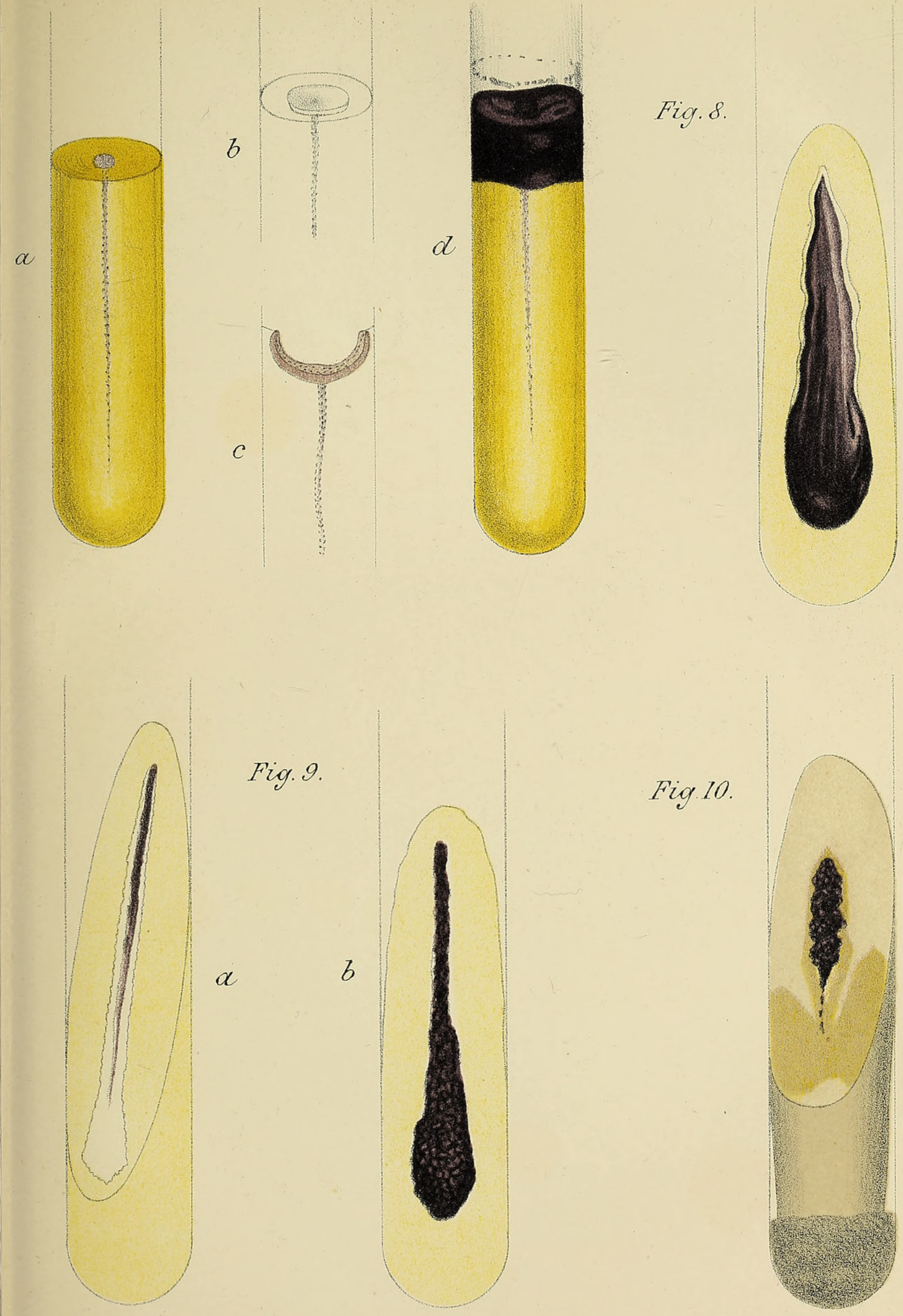

Fig. 10

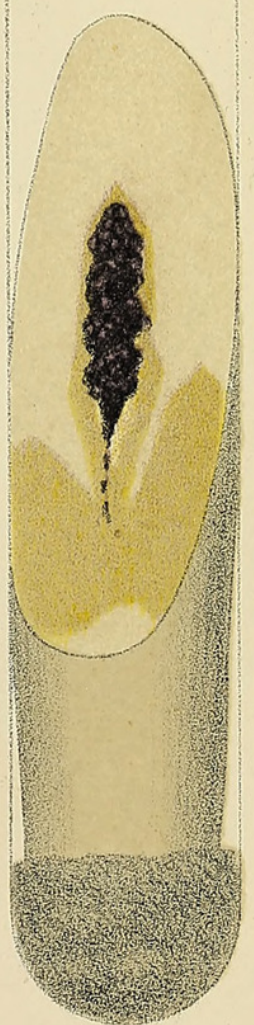

University Press, Oxford. 


\section{$2 \mathrm{BHL}$ Biodiversity Heritage Library}

Ward, H. Marshall. 1898. "A violet Bacillus from the Thames." Annals of botany 12, 59-74. https://doi.org/10.1093/oxfordjournals.aob.a088684.

View This Item Online: https://www.biodiversitylibrary.org/item/233102

DOI: https://doi.org/10.1093/oxfordjournals.aob.a088684

Permalink: https://www.biodiversitylibrary.org/partpdf/318492

\section{Holding Institution}

Smithsonian Libraries

\section{Sponsored by}

Biodiversity Heritage Library

\section{Copyright \& Reuse}

Copyright Status: Not in copyright. The BHL knows of no copyright restrictions on this item.

This document was created from content at the Biodiversity Heritage Library, the world's largest open access digital library for biodiversity literature and archives. Visit BHL at https://www.biodiversitylibrary.org. 